\title{
Inositol Niacinate
}

National Cancer Institute

\section{Source}

National Cancer Institute. Inosito/ Niacinate. NCI Thesaurus. Code C75996.

A niacin formulation that contains no free niacin, but can be hydrolyzed to release free niacin in vivo. Use of inositol niacinate is associated with less flushing than that seen with the use of free niacin. 